\section{PDM ¿complemento, impugnador o aliado del DSM?}

Estimado Sr. Editor,

El diagnóstico en psiquiatría sufrió un terremoto con la aparición del DSM-III en 1980 que, sin constituir una novedad fundamental desde el punto de vista epistemológico fue precedido por los Criterios Diagnósticos de Feighner et al, y el RDC quienes, a su vez, se apoyaron en la psicopatología clásica de Kurt Schneider, sistematizó lo conocido, estableció criterios diagnósticos explícitos, favoreció la investigación centrada en la validez y confiabilidad pero, sobre todo, hizo sentir que por fin la especialidad se incorporaba al mundo de la ciencia médica ${ }^{1-4}$. El DSM-IV-TR ha continuado la senda, respondiendo esta vez desde la seguridad de lo establecido; vale decir, examinando a los problemas surgidos con posterioridad, a partir de los hallazgos empíricos y las críticas metodológicas y conceptuales, sin olvidar la continuación de unificación de terminología y descripciones nosológicas con el ICD-10 hasta donde es posible, porque ambas clasificaciones gozan de un prestigio en el ámbito de la investigación ${ }^{5,6}$. Cualesquiera sean sus insuficiencias o sesgos, resulta innegable que existe un antes y un después del DSM, y tanto los datos clínicos como propuestas terapéuticas, aún fuera de Norteamérica, desde ahora se deben referir a él obligadamente.

El psicoanálisis ha recogido el duro reto de ofrecer una alternativa basándose en sus cien años dedicados desde Freud mismo a desarrollar una nosología que sea por igual validable empíricamente, pero psicodinámicamente concebida y ejecutada. De aquí nacen los atributos y las diferencias explícitas del Manual Diagnóstico Psicodinámico ( $\mathrm{PDM}$ ): taxonomía de personas (no trastornos), dimensional (no categorial), espectro que va desde lo neurótico pasando por lo limítrofe hasta alcanzar lo psicótico (no ausencia de jerarquía), lo que hace que el individuo sea único (no un diagnóstico compartido con otros), buscar significado (no síntomas observables conductualmente), conseguir coherencia interna a la organización caracterológica (no comorbilidad), basado en la teoría psicoanalítica (no ateorético), en suma, formulación de cada caso como individual e irrepetible con el propósito de planificar la psicoterapia (y otros tratamientos) abarcando la totalidad del funcionamiento cognitivo, emocional y conductual del paciente ${ }^{7}$.

El PDM consta de tres ejes destinados a describir las complejas interrelaciones del funcionamiento global del paciente y las maneras como se compromete en el proceso terapéutico. El Eje P corresponde a la Dimensión I: Patrones y trastornos de la personalidad, que permite ubicar a la persona dentro de un continuo desde el funcionamiento más sano hasta el más alterado. El Eje M expresa la Dimensión II: Funcionamiento mental; investiga con una atenta mirada microscópica el procesamiento de información y autoregulación, formación y mantención de las relaciones, organización de la experiencia y diferentes niveles de expresión de los afectos y emociones, representación y diferenciación de la experiencia, estrategias de manejo y defensa, observación de sí-mismo y de los otros y, por último, formación de los estándares internos. El Eje S constituye la Dimensión III: Síntomas y preocupaciones; aquí se parte de las categorías del DSMIV-TR aunque se enfatiza la experiencia personal del paciente medida en sus estados afectivos, procesos cognitivos, experiencias somáticas y patrones relacionales.

El psicoanálisis como institución científica se las juega a fondo frente a la férrea, potente y cohesionada organización de la psiquiatría americana. De hecho son cinco las poderosas asociaciones o academias psicoanalíticas que están sustentando el proyecto PDM. Se acude a propuestas o sistemas nosológicos empíricos psicoanalíticamente desarrollados durante largos años por diferentes grupos de trabajo repartidos por el mundo con el fin de avalar experimentalmente sus formulaciones: ORI, SWAP y OPD ${ }^{8-11}$. Pero no es difícil comprender que se trata de una lucha de titanes empeñados en resolver sus diferencias que dura cerca de treinta años, más que en probar los asertos y méritos del psicoanálisis o 
cuestionar en profundidad las carencias del DSM. Por las confesiones del gran promotor del DSMIII Robert Spitzer, sabemos de las luchas que el comité hubo de mantener contra los psicoanalistas que estaban enquistados al interior de la Asociación Psiquiátrica Americana para imponer su concepción clasificatoria ${ }^{12}$. En Europa, la situación fue distinta por motivos históricos el psicoanálisis no gozaba del poder ni popularidad al interior de la psiquiatría académica, aunque igualmente se generó una disputa de proporciones para tolerar la nosología americana ${ }^{13}$.

La conclusión es que el PDM busca mejorar el DSM en lo que a este le falta antes que en poner en entredicho sus principales asertos o en afirmar con decisión su propia posición teórica, y esta es, por lo demás, su declaración de principios, que colocan rápidamente en las primeras líneas del manual, aunque agrega al pasar que también persigue convertirse en complemento útil del ICD ¿Motivo razonable? Evidentemente. ¿Impulsa esta postura el desarrollo de la psiquiatría como ciencia empírica? Si y no. Si, porque el psicoanálisis tiene mucho que decir acerca de la intimidad recóndita del hombre espiritualmente enfermo y de la manera de abordar todos sus conflictos emocionales, dimensiones que no aparecían en el $\mathrm{DSM}^{14}$. No, porque sus logros substantivos quedan algo deslavados en su mezcla indiscriminada con los hallazgos del DSM, como queda especialmente claro en el eje $\mathrm{S}$ de la Experiencia subjetiva, que a ratos se limita a resumir sin finura psicodinámica los principales cuadros clínicos.

El PDM deja un sabor agridulce. Tantos años de espera no justifican este manual que parece incompleto, difícil de operar como para conseguir la suficiente confiabilidad entre distintos clínicos, con una validez externa cuestionable y que no aporta todo el conocimiento y experiencia adquiridos desde los tiempos de Freud. Un examen atento a las pocas viñetas clínicas enseña que las pautas son poco iluminadoras, ambiguas y por momentos no útiles para la práctica cotidiana del terapeuta, especialmente si este lleva a cabo una psicoterapia profunda. Por decirlo así, la meta era saltar a lo cuantitativo en lo posible mensurable objetivamente, pero se permaneció en lo narrativo disfrazado bajo un ropaje que exhibe códigos con números como prueba de su compromiso con la ciencia dura. Como es de esperar, este PDM estará necesitado de un PDM-II después de un período de experimentación estricto por parte de los psicoterapeutas activos en el área de la investigación, de estudios de campo en las diferentes partes del mundo donde se practique la psicodinamia de forma seria y responsable.

\section{Referencias}

1. Schneider K. Klinische Psychopathologie. 7. Auflage. Stuttgart: Thieme, 1967.

2. American Psychiatric Association. Diagnostic and Statistical Manual of Mental Disorders, Third Edition. Washington, DC: American Psychiatric Association, 1980.

3. Feighner J P, Robins E, Guze S B, Woodruf R A, Winokur G, Muñoz R. Diagnostic criteria for use in psychiatric research. Arch Gen Psychiatry 1972; 26: 57-63.

4. Spitzer R L, Endicott J, Robins E. Research diagnostic criteria: Rationale and reliability. Arch Gen Psychiatry 1978; 35: 773-81.

5. American Psychiatric Association. Diagnostic and Statistical Manual of Mental Disorders, Fourth Edition, Text Revision. Washington, DC: American Psychiatric Association, 2000.

6. World Health Organization. The ICD-10 Classification of Mental and Behavioural Disorders. Clinical descriptions and diagnostic guidelines. Geneva: World Health Organization, 1992.

7. PDM Task Force. Psychodynamic Diagnostic Manual. Silver Spring, MD: Alliance of Psychoanalytic Organizations, 2006.

8. Cierpka M, Stasch M, Dahlbender R W. El sistema Diagnóstico Psicodinámico Operacionalizado (OPD). Concepto, confiabilidad y validez. Rev Chil Neuro-Psiquiat 2006; 44: 105-25.

9. Westen D, Shedler J. Revising and assessing Axis II: Developing a clinically and empirically valid 
assessment method. Am J Psychiatry 1999; 156: 256-78.

10. Westen D, Shedler J. Revising and assessing Axis II: Toward an empirically based and clinically useful classification of personality disorders. Am J Psychiatry 1999; 156: 273-99.

11. Blatt S J, Levy K N. A psychodynamic approach to the diagnosis of psychopathology. En: Barron JW, Ed. Making diagnosis meaningful. Washington, DC:
American Psychological Association, 1998. p. 73109.

12. Wilson M. DSM-III and the transformation of American Psychiatry: A History. Am J Psychiatry 1993; 150: 399-410.

13. Pichot P J. DSM-III and Its Reception: A European View. Am J Psychiatry 1997; 154: 47-54.

14. Tucker G J. Putting DSM-IV in Perspective. Am J Psychiatry 1998; 155: 159-61.

Gustavo Figueroa C. gufigueroa@vtr.net 